\title{
THE EFFECT OF AN IMPERMEABLE VAPOR BARRIER ON ELECTROLYTE AND NITROGEN CONCENTRATIONS IN SWEAT ${ }^{1}$
}

\author{
By CHARLES R. KLEEMAN,² DAVID E. BASS, AND MURRAY QUINN * \\ (From the Department of the Army, Qwartermaster Climatic Research Laboratory, \\ Lawrence, Massachusetts)
}

(Submitted for publication February 16, 1953; accepted April 24, 1953)

When environmental temperatures are high, 80 to 90 per cent of the total water, sodium, and chloride, and 25 to 50 per cent of the losses of potassium, calcium, magnesium, and nitrogen may occur in the sweat $(1,2)$. Failure to measure these losses may lead to serious errors in balance studies. Although dermal water loss can' be quite accurately measured in both acute and prolonged studies, this is not true of sweat electrolytes and nitrogen. Even in metabolic balance studies where the subject's daily activities are rigidly controlled, the accurate collection of all body sweat solutes by repeated body washings presents obvious difficulties. Conn and Louis ( 3 ) and Johnson, Pitts, and Consolazio (4) have assumed that the dermal losses are equal to the intake-(urine plus fecal losses). This method, however, disregards any daily positive or negative balances of these substances which may occur. The simplest method involves the collection of a local sweat sample, measurement of the solute concentration, and determination of the total solute content from the concentration and the total sweat loss. This method assumes that the local sample is representative of the total body sweat and that the technique of collection does not alter the true solute concentrations. Previous investigations $(5,6,7,8)$ and data from this Laboratory (7) indicate that neither of these assumptions is correct. In general, previous studies $(5,6,7,8,9)$ indicate that the chloride, nitrogen, and lactic acid concentrations of arm sweat collected under an impermeable barrier, are higher than the concentrations of these solutes in total body sweat. Mickelsen and Keys (6) have shown that the concentrations of chloride ion, urea, and

\footnotetext{
1 Presented in part at the fall meeting of the American Physiological Society in New Orleans, September, 1952.

2Present address: Department of Internal Medicine, Yale University School of Medicine, New Haven, Conn. 3 1st Lieutenant, Medical Corps.
}

lactic acid are different in sweat samples collected under identical conditions from different body areas. They also noted that the concentration of chloride ion in hand sweat collected in a rubber glove is 38 to 72 per cent higher than the mean concentration of chloride ion in sweat collected from the entire body by repeated washings.

In contrast, Ladell (5) found surprisingly good agreement between the loss of chloride in sweat calculated from arm bag concentrations and sweat rate and the value obtained from total body washings.

In view of the conflicting results of previous investigators, the present study was undertaken to reevaluate the effect of an impermeable barrier, such as a plastic arm bag on the sodium, potassium, chloride, and total nitrogen concentrations of thermal sweat and to determine whether the concentration of solutes in arm bag sweat could be used to calculate total dermal electrolyte and nitrogen losses.

\section{METHODS}

Twenty-seven experiments were performed on 17 men. Although the precise state of acclimatization to heat was not known in these subjects, one group of experiments was performed during the fall (Group A) and the other (Group B) during the summer. Each experiment consisted of a one- to two-hour exposure at $120^{\circ} \mathrm{F}$. with a relative humidity of 28 to 30 per cent. In an effort to prevent the loss of any body sweat by means other than evaporation, the men were clothed in light cotton pajama-type drawers, the lower end being tucked into long woolen socks, covered over with polyethylene foot bags inside of combat boots. Large cotton bath towels, folded in strip fashion, were tied around the chest and the uninclosed upper arm. Each subject carried an additional towel in his hand for wiping off his face and neck. In all subjects, sweat was collected during the entire heat exposure from one arm in polyethylene bags which were sealed at the level of the insertion of the deltoid muscle. During the period of sweat collection, the subject alternated periods of walking on a horizontal motor- 
driven treadmill at four mph with rest. The alternate periods were fifteen to twenty minutes in duration.

The experiments were divided into two groups. In Group A (twelve experiments), the subjects were exposed in the nude to the heat for a 15- to 30-minute period to initiate sweating and "flush" the lumens of the sweat glands and the surface of the skin. Following this brief heat exposure each subject showered. After this he was rinsed with three to five liters of distilled water, dried, weighed to \pm 10 grams and reentered the heat, appropriately dressed, with the polyethylene bag on one arm. In Group B (15 experiments), no preliminary exposure to heat was employed. In this group, therefore, sweat collections were begun without prior "flushing" of sweat gland lumens. The remainder of the procedure was similar to that employed for Group A.

The arm bag was removed at the end of the exposure to heat in all 27 experiments. The sweat was mixed thoroughly in the bag by shaking, filtered into polyethylene bottles, and the volume measured. The solutes of the total body sweat were recovered by washing each man as he stood or kneeled in a large porcelain bathtub with 15 to 20 liters of distilled or tap water.4 The subjects were then dried and reweighed. The plastic bag, all towels, and clothing utilized to collect sweat during the heat exposure were added to the wash water in which they were thoroughly rinsed.

The final volume of the wash water was determined by adding $500 \mathrm{mgm}$. of antipyrine and calculating the volume from the dilution of antipyrine. Electrolyte and nitrogen concentrations were determined in the arm bag sweat and in the final wash water. Sodium and potassium were determined on a Beckman flame photometer, correction being made in the standards for mutual excita-

4 The tap water was analyzed for its content of sodium, chloride, potassium, and nitrogen. tion of sodium and potassium. Chloride was determined by the Schales and Schales method (10), or a modification of the Volhard silver nitrate procedure (11), and total nitrogen by the Conway microdiffusion method (12).

\section{Method of calculation}

a) Sweat loss $(\mathrm{Kg})=$. Weight - Respiratory $\mathrm{H}_{2} \mathrm{O}$ loss. 5

b) Arm bag content of each solute $=$ Volume of sweat collected in the arm bag $\times$ concentration of the individual solute in arm bag sweat.

c) Calculated solute loss $=$ Sweat loss $(\mathrm{Kg}$.$) \times con-$ centration of the individual solute in arm bag sweat.

d) Solute recovered from the total body $=$ (Volume of wash water $X$ concentration of the solute in the wash water) + Arm bag content of each solute (b).

e) Concentration of the measured solute in total body sweat $=$ Solute recovered (d)/Sweat loss $\mathrm{Kg}$. (a).

\section{RESULTS}

The results are summarized in Tables I and II. Sweat rate. No significant correlations were noted between sweat rate and the arm or total body concentrations of the various solutes studied. Previous investigators $(4,7,13,14,15)$, however, have demonstrated close correlations between sweat

5 Respiratory water loss was calculated by determining the ventilation rate of the subjects while walking on the treadmill and at rest; the rates were corrected to body temperature and the expired air was assumed to be saturated with water vapor at $37^{\circ} \mathrm{C}$. This assumption introduces a small error since expired air need not be saturated.

TABLE I

Comparison of sweat concentrations from arm and total body (Group A)

\begin{tabular}{|c|c|c|c|c|c|c|c|c|c|}
\hline No. & Sweat rate & $\mathrm{Na}^{+}(1) *$ & $\mathrm{Na}^{+}(2) *$ & $\mathrm{~K}^{+}(\mathbf{1})$ & $\mathrm{K}^{+}(2)$ & $\mathrm{Cl}^{-}(1)$ & $\mathrm{Cl}^{-}$(2) & $N(1)$ & $\mathbf{N}(2)$ \\
\hline \multirow[t]{2}{*}{$\begin{array}{r}1 \\
2 \\
3 \\
4 \\
5 \\
6 \\
7 \\
8 \\
9 \\
10 \\
11 \\
12\end{array}$} & $\begin{array}{r}c c . / h r . \\
1,275 \\
752 \\
554 \\
917 \\
536 \\
1,235 \\
1,168 \\
873 \\
1,204 \\
1,316 \\
2,036 \\
822\end{array}$ & $\begin{array}{r}m E q . / L . \\
65.9 \\
103.2 \\
114.0 \\
115.4 \\
72.8 \\
45.4 \\
36.1 \\
29.4 \\
61.0 \\
73.5 \\
61.6 \\
94.7\end{array}$ & $\begin{array}{c}m E q . / L . \\
51.2 \\
75.0 \\
72.8 \\
77.3 \\
56.7 \\
45.2 \\
40.5 \\
32.3 \\
52.9 \\
63.8 \\
51.2 \\
86.9\end{array}$ & $\begin{array}{c}m E q . / L . \\
4.6 \\
9.0 \\
15.8 \\
6.4 \\
5.9 \\
6.1 \\
5.7 \\
5.9 \\
6.1 \\
7.1 \\
4.2 \\
6.4\end{array}$ & $\begin{array}{c}m E q . / L . \\
3.1 \\
4.9 \\
6.7 \\
4.1 \\
5.1 \\
4.7 \\
4.0 \\
4.9 \\
5.0 \\
5.8 \\
3.1 \\
5.3\end{array}$ & $\begin{array}{r}\boldsymbol{m E q .} / \boldsymbol{L} . \\
58.3 \\
86.3 \\
92.5 \\
101.6 \\
64.9 \\
39.1 \\
29.9 \\
24.6 \\
51.9 \\
63.7 \\
53.7 \\
81.8\end{array}$ & $\begin{array}{c}E q . / L . \\
43.2 \\
65.3 \\
59.5 \\
68.5 \\
49.4 \\
37.0 \\
30.0 \\
22.0 \\
44.9 \\
54.9 \\
41.9 \\
70.1\end{array}$ & $\begin{array}{c}\text { mgm. \% } \\
41.3 \\
56.5 \\
42.1 \\
50.8 \\
45.3 \\
55.3 \\
43.0 \\
39.3 \\
40.5 \\
31.0 \\
54.6\end{array}$ & $\begin{array}{c}g m . \% \\
28.3 \\
35.0 \\
31.5 \\
41.1 \\
39.9 \\
31.1 \\
37.1 \\
37.2 \\
27.1 \\
24.4 \\
40.1\end{array}$ \\
\hline & $\begin{array}{c}\text { Mean } \\
\text { S.D. } \\
\text { Significance of } \\
\text { differences }\end{array}$ & $\begin{array}{r}72.7 \\
\pm 28.9 \\
P\end{array}$ & $\begin{array}{r}58.8 \\
\pm 16.5 \\
.01\end{array}$ & $\begin{array}{r}6.9 \\
\pm 3.0\end{array}$ & $\begin{array}{r}4.7 \\
\pm 1.0\end{array}$ & $\begin{array}{r}62.4 \\
+24.5\end{array}$ & $\begin{array}{r}48.9 \\
\pm 15.3\end{array}$ & $\begin{array}{r}45.4 \\
\pm 8.0\end{array}$ & $\begin{array}{r}33.8 \\
\pm 5.7\end{array}$ \\
\hline
\end{tabular}

* (1) = Concentration of a given solute in arm bag sweat.

(2) = Concentration of a given solute in sweat recovered from the entire body. 
CHARLES R. KLEEMAN, DAVID E. BASS, AND MURRAY QUINN

TABLE II

Comparison of sweat concentrations from arm and total body (Group B)

\begin{tabular}{|c|c|c|c|c|c|c|c|c|c|}
\hline No. & Sweat rate & $\mathrm{Na}^{+}(1) *$ & $\mathrm{Na}^{+}(2)^{*}$ & $\mathrm{~K}^{+}(1)$ & $\mathbf{K}^{+}(\mathbf{2})$ & $\mathrm{Cl}^{-}(1)$ & $\mathrm{Cl}^{-}(2)$ & $N(1)$ & $\mathbf{N}(2)$ \\
\hline $\begin{array}{r}1 \\
2 \\
3 \\
4 \\
5 \\
6 \\
7 \\
8 \\
9 \\
10 \\
11 \\
12 \\
13 \\
14 \\
15\end{array}$ & $\begin{array}{r}c c . / h r . \\
1,058 \\
912 \\
914 \\
1,315 \\
1,249 \\
978 \\
913 \\
1,225 \\
1,220 \\
850 \\
1,094 \\
1,192 \\
522 \\
494 \\
549\end{array}$ & $\begin{array}{c}m E q . / L . \\
72.2 \\
81.6 \\
29.4 \\
59.0 \\
72.4 \\
59.0 \\
74.8 \\
94.6 \\
42.4 \\
68.0 \\
60.5 \\
58.9 \\
32.9 \\
19.0 \\
49.2\end{array}$ & $\begin{array}{c}E q . / L . \\
54.8 \\
60.0 \\
21.4 \\
34.3 \\
52.4 \\
49.4 \\
44.9 \\
49.5 \\
33.5 \\
42.3 \\
42.1 \\
43.6 \\
21.1 \\
13.8 \\
37.9\end{array}$ & $\begin{array}{c}E q . / L . \\
8.7 \\
9.4 \\
7.3 \\
5.9 \\
11.1 \\
7.8 \\
12.4 \\
15.0 \\
5.8 \\
9.7 \\
8.2 \\
7.8 \\
7.2 \\
8.7 \\
6.9\end{array}$ & $\begin{array}{c}E q . / L . \\
6.3 \\
6.4 \\
5.2 \\
5.2 \\
5.0 \\
4.4 \\
4.6 \\
6.3 \\
4.0 \\
5.1 \\
5.8 \\
5.6 \\
3.5 \\
4.4 \\
4.3\end{array}$ & $\begin{array}{c}m E q . / L . \\
70.1 \\
79.6 \\
25.0 \\
54.4 \\
70.3 \\
56.9 \\
69.8 \\
88.1 \\
41.4 \\
67.9 \\
62.4 \\
60.7 \\
24.6 \\
12.3 \\
41.7\end{array}$ & $\begin{array}{c}m E q . / L . \\
59.8 \\
64.3 \\
24.3 \\
49.0 \\
55.2 \\
54.2 \\
52.6 \\
57.1 \\
44.6 \\
50.7 \\
44.0 \\
49.1 \\
18.1 \\
12.9 \\
33.2\end{array}$ & $\begin{array}{c}g m . \% \\
65.4 \\
63.2 \\
49.0 \\
38.9 \\
49.3 \\
43.5 \\
115.8 \\
5 \overline{55.5} \\
57.6 \\
29.4 \\
48.0 \\
74.0 \\
81.3 \\
53.8\end{array}$ & $\begin{array}{c}g m . \% \\
37.5 \\
29.8 \\
26.1 \\
26.2 \\
34.0 \\
23.5 \\
29.1 \\
31.6 \\
20.0 \\
17.2 \\
32.5 \\
25.8 \\
18.6 \\
22.4\end{array}$ \\
\hline & \multirow{2}{*}{$\begin{array}{c}\text { Mean } \\
\text { S.D. } \\
\text { Significance of } \\
\text { differences }\end{array}$} & $\begin{array}{r}58.6 \\
\pm 20.7\end{array}$ & $\begin{array}{r}40.1 \\
\pm 13.3\end{array}$ & $\begin{array}{r}8.8 \\
\pm 2.4\end{array}$ & $\begin{array}{r}5.1 \\
\pm .9\end{array}$ & $\begin{array}{r}55.0 \\
\pm 23.4\end{array}$ & $\begin{array}{r}44.6 \\
\pm 15.5\end{array}$ & $\begin{array}{r}58.9 \\
\pm 21.3\end{array}$ & $\begin{array}{r}26.7 \\
\pm 5.9\end{array}$ \\
\hline & & \multicolumn{2}{|c|}{$\mathbf{P}<.001$} & \multicolumn{2}{|c|}{$P<.001$} & \multicolumn{2}{|c|}{$\mathrm{P}<.001$} & \multicolumn{2}{|c|}{$\mathrm{P}<.001$} \\
\hline
\end{tabular}

* See footnote, Table I.

rates and sodium and chloride concentrations in any given individual under different states of acclimatization and at different environmental temperatures. In the present study similar correlations might have been noted if sweat rates had been cor- rected for surface area, and if each subject had been compared with himself at different environmental temperatures and different sweat rates. Sodium and chloride. The mean sodium concentration of arm bag sweat was $72.7 \mathrm{mEq}$. per L. for

\section{SODIUM ION REGRESSION LINE}
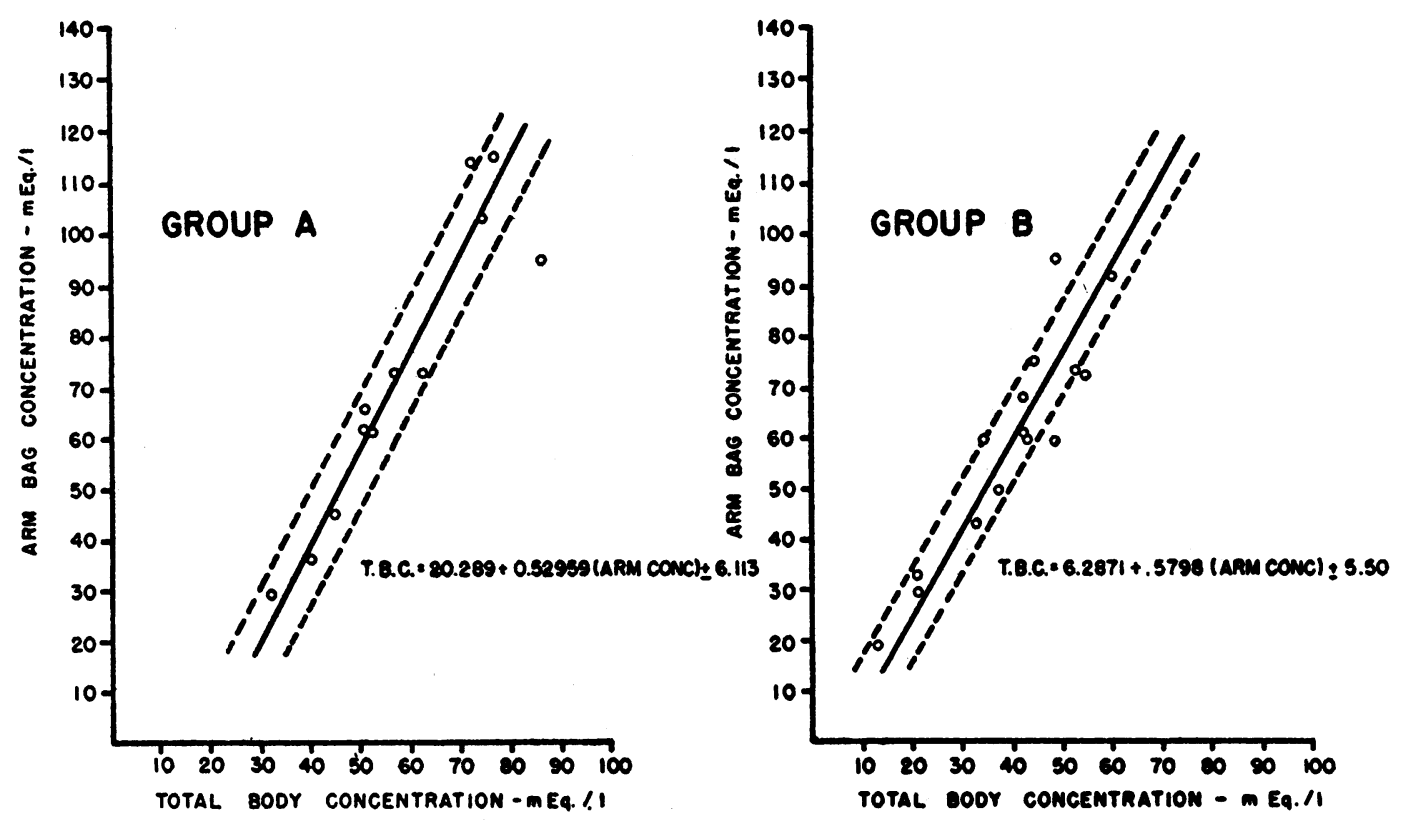

FIG. 1 


\section{CHLORIDE ION REGRESSION LINE}
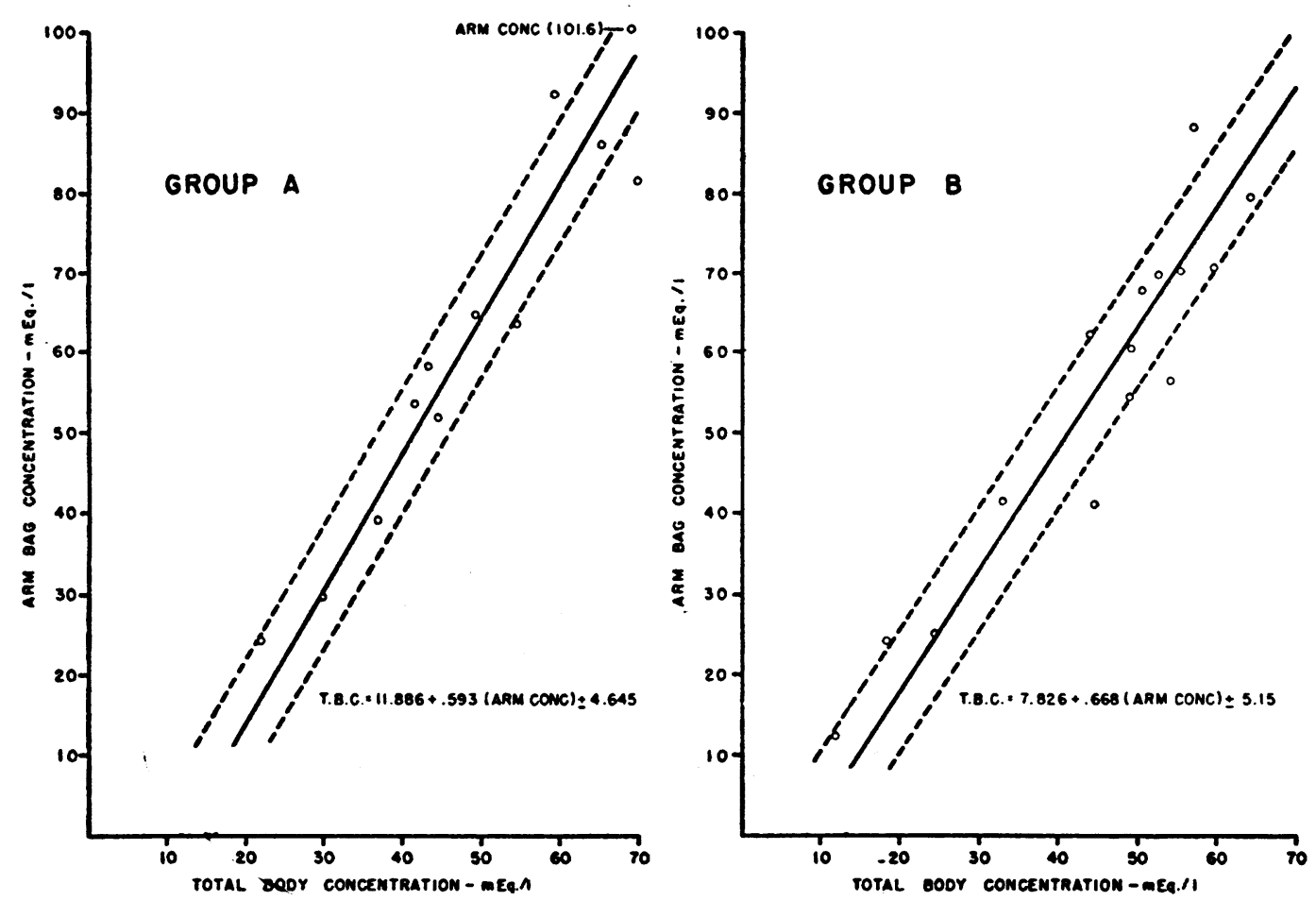

FIG. 2

Group $A$ and $58.6 \mathrm{mEq}$. per L. for Group B. The mean sodium concentration of total body sweat was $58.8 \mathrm{mEq}$. per L. for Group A and $40.1 \mathrm{mEq}$. per L. for Group B. The differences (between Groups A and B) in total body and arm bag sweat concentrations might have resulted in part from the difference in the preliminary "flushing" procedure, as well as the element of heat acclimatization. Group B experiments were performed during the summer, and Group A experiments were performed during the late fall (16). In both groups the mean total body concentration was appreciably lower than the arm bag concentration. These differences were highly significant. In general, the chloride concentrations of the sweat in both groups followed a pattern similar to that observed for sodium. However, it should be noted (Tables I and II) that the sodium concentration of arm bag sweat exceeded the chloride concentration in every instance, but the chloride concentration of total body sweat exceeded the sodium concentration of total body sweat in twelve of the 27 experiments. From the data of Tables
I and II it appeared that the lower the arm bag sweat concentrations of sodium and chloride the closer was the agreement with total body concentrations. Therefore, regression equations were formulated relating the concentrations of sodium and chloride in total body sweat to those in arm bag sweat (Figures 1 and 2). These equations and lines validated the above observations. There appeared to be very little difference between Groups A and B with respect to the chloride slope; however, the slope obtained for sodium in Group A demonstrated closer agreement than Group B between the calculated and actual recovery of sodium.

Potassium. The mean potassium concentration in arm bag sweat for Groups A and B was 6.93 $\mathrm{mEq}$. per L. and $8.77 \mathrm{mEq}$. per L., respectively, whereas the mean concentration in total body sweat for these groups was $4.71 \mathrm{mEq}$. per L. and $5.08 \mathrm{mEq}$. per L., respectively. Again these differences between total body and arm bag concentrations were highly significant. It was noted in both groups (Tables I and II) that the potassium 
concentration in arm bag sweat in many cases greatly exceeded normal plasma potassium levels, whereas in only four instances was the concentration in total body sweat as high as $6 \mathrm{mEq}$. per $\mathrm{L}$. The remainder ( 82 per cent) were all in the normal plasma range.

The mean difference between total body and arm bag sweat concentrations for Group A was appreciably smaller than the mean difference in Group B. In contrast to the findings on sodium and chloride, there was no apparent improved agreement between arm and body sweat concentrations of potassium with lower arm bag values (Figure 3). In general, regardless of the variation in arm bag concentrations, the total body concentrations fell within a narrow range. Group A differed from Group B not only in having a smaller average difference between arm and total body sweat concentration, but also in showing a smaller spread of arm bag values (Figure 3 ).
Nitrogen. The concentrations of nitrogen in arm bag and total body sweat followed a pattern very similar to that previously described for potassium. They did not demonstrate the arm-body correlations shown by sodium and chloride (Figure 4) and the differences between Groups A and $B$ noted for potassium were also noted for nitrogen (Tables I and II and Figure 4).

\section{DISCUSSION}

The two main factors which may have given rise to the differences in the concentrations of solute in arm and total body sweat were (1) errors in technique and (2) unknown and/or uncontrollable physiologic variables. In recovering solutes from total body sweat, loss of liquid sweat from the skin surface during the exposure to heat, and incomplete washing constitute major sources of error. The former was minimized in the present study by the use of a low relative humidity

\section{POTASSIUM ION REGRESSION LINE}
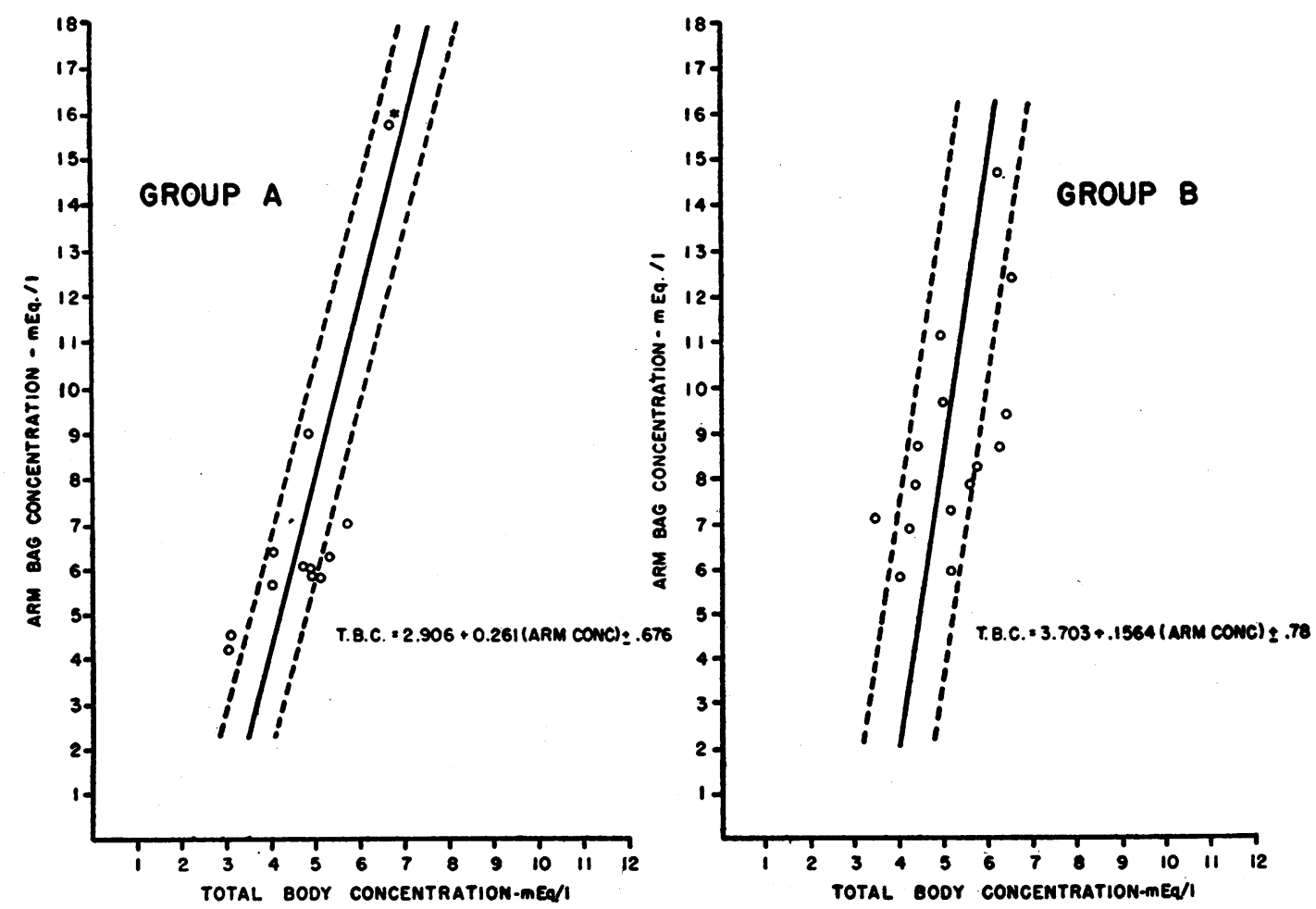

FIG. 3

This subject with the highest arm bag potassium concentration in Group $A$ had a surprisingly low arm sweat volume. This made thorough mixing of his arm bag sweat difficult. 


\section{TOTAL NITROGEN REGRESSION LINE}
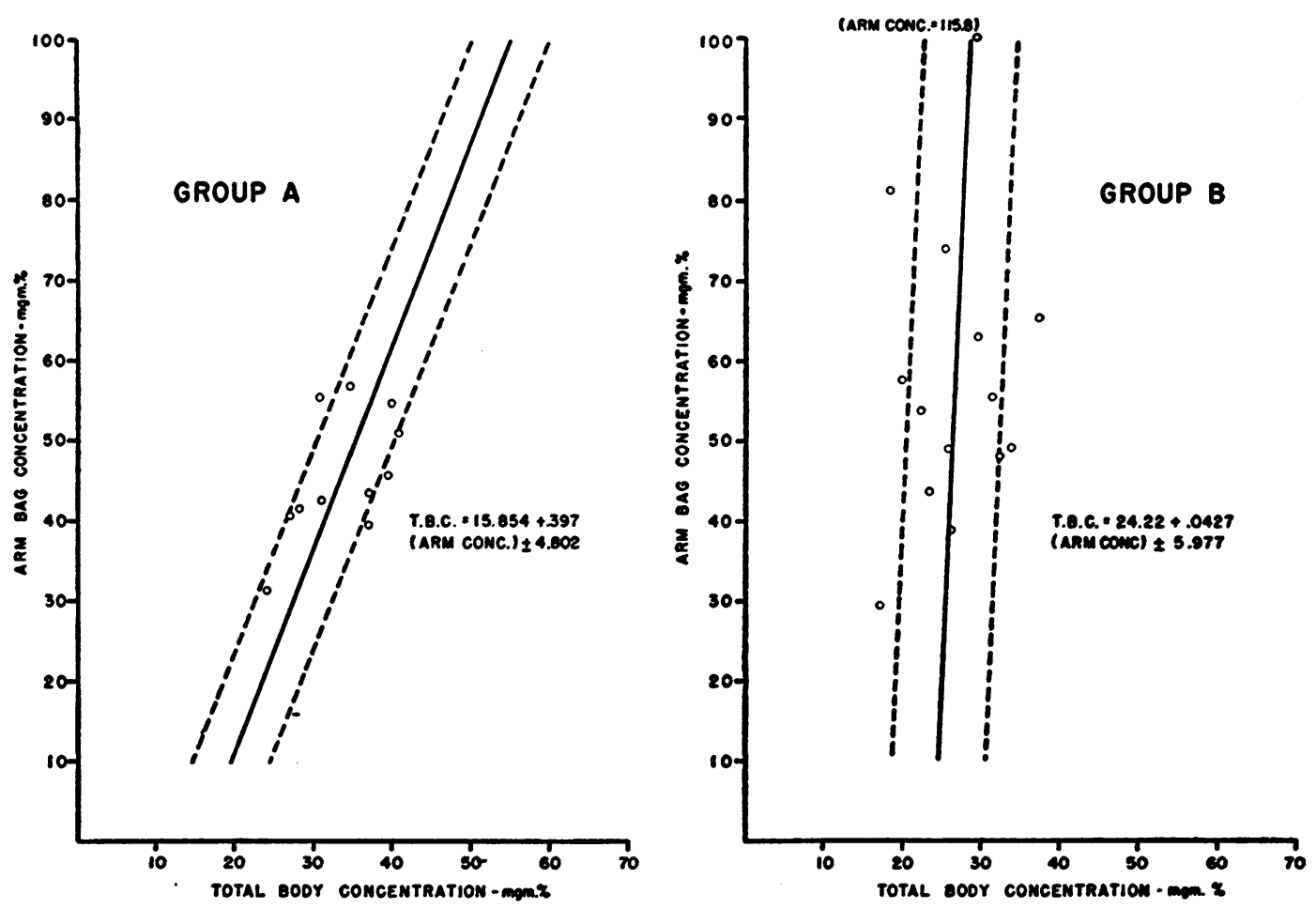

FIG. 4

which enhanced evaporation and by the use of towels and underwear to soak up the sweat. In this study 15 to 20 liters of water were used in washing each man. This was considerably more water than has been used in previous studies of this type $(5,7,8,15)$ in which complete recovery of all sweat solute on the body surface has been demonstrated. Errors in determining the volume of wash water were minimized by measuring the dilution of known amounts of antipyrine added to the wash water. Errors in solute concentration in arm bag sweat could occur if, (1) the sweat collected in the dependent part of the bag was not thoroughly mixed with the water vapor which had condensed along the walls of the plastic bag, and (2) if this condensed water vapor did not mix with the more concentrated sweat on the skin surface. These errors were minimized by thorough mixing of the sweat in the bag after it was removed from the arm and by constant movement of the arm in contact with the inner surface of the bag while the subjects walked the treadmill. In calculating sensible sweat losses by difference in weight, correc- tion should be made for other avenues of weight change. Since no fluids were taken by mouth and no urine or feces were passed between weighings, no correction was necessary for these sources of weight change. Insensible water loss $^{\circ}$ was a necessary correction. Calculated respiratory water loss averaged about 70 grams per hour in this study, and at the high sweat rates noted, even large percentage errors in respiratory water loss would have altered the calculated sweat losses very little. Insensible water loss through the skin theoretically stops when the skin surface is covered with moisture (16). However, the low humidity present in this study is conducive to rapid evaporative losses, leading to concentration of the sweat solute on the skin surface. This may have enhanced osmotic water loss through the skin. This loss cannot be quantitated, but probably represents negligible volume.

The concentrations of the solutes in total body sweat determined in this study were in the ranges

\footnotetext{
- Insensible water loss is defined as a dermal or pulmonary loss of water vapor without solute.
} 
noted by numerous other investigators who collected sweat solutes in a similar manner $(5,6,8$, $17,18,19,20,21)$. Inspection of the data emphasizes the large dermal losses of electrolytes and nitrogen that may occur during high rates of sweating. Metabolic balance studies conducted in this Laboratory (2) during which subjects were exposed to high temperatures for 24-hour periods have demonstrated maximal sweat losses of sodium and chloride of $400 \mathrm{mEq}$., potassium $60 \mathrm{mEq}$., and nitrogen 5 grams per 24 hours. Under conditions similar to those of the present study the large errors involved in utilizing arm bag sweat concentrations of sodium, chloride, potassium, and nitrogen in determining total body sweat losses and metabolic balances are readily apparent.

Because of the ease of collection of arm bag sweat it was hoped that some constant relationship could be demonstrated between the concentration of solutes in arm and total body sweat. Under the experimental conditions used in both Groups A and $\mathrm{B}$, total body sweat sodium and chloride concentrations could be fairly well predicted from the arm bag concentrations using the formulated regression equations (Figures 1 and 2). From the standard errors of estimate of these equations, the accuracy of prediction is, however, not very high.

Examination of the data of various investigators as summarized by Dill (13) showed that the lower the concentration of chloride in hand sweat, the more closely did it agree with the concentration of chloride in the total body sweat. The subjects in whom Ladell (5) found good correlations between recovered and calculated sweat chloride loss were probably acclimatized to heat and they all showed relatively low chloride concentrations in the arm bag sweat. In the present study, it is precisely in this group that the closest correlation between chloride concentrations in arm and total body sweat were noted.

In a recent study, van Heyningen and Weiner (8) demonstrated that the arm bag chloride, urea, and lactate concentrations always exceeded the concentrations of these substances in total body sweat. They, however, collected their arm bag sweat by draining it off at intervals from the bottom of the bag, a process that probably would lead to excessive concentration of the sweat as a result of water vapor condensation on the sides of the bag. The lowest arm bag chloride concentration given in their study was $81 \mathrm{mEq}$. per $\mathrm{L}$.

It is difficult to explain the closer agreement between arm bag and total body sweat concentrations of sodium and chloride associated with lower arm bag concentrations. Sodium and chloride concentrations of sweat collected under an impermeable barrier $(8,22)$ are influenced by local factors such as the skin temperature and the vapor pressure under the barrier, and systemic factors such as adrenal cortical activity, state of acclimatization, dietary salt content, etc. If the lower sodium and chloride concentrations were an indication of greater systemic influence on sweat gland activity, this influence would exceed that of the local environmental factors created under the bag. A closer correlation between arm bag and total body concentration would then be noted. A closer correlation at lower concentrations would also be noted if a constant volume of sweat water in the bag repenetrated the skin. The absolute change in water to solute relationship would have a greater effect the higher the original solute concentration in the sweat. Although the present study offered no means of assessing the contribution of these factors, our failure to obtain correlations for arm and total body nitrogen and potassium similar to those found for sodium and chloride suggested that there was some selective action on the sodium and the chloride ions.

In general, the total body potassium concentration fell within the narrow range of approximately 4 to $6 \mathrm{mEq}$. per L., whereas the concentration in the arm bag sweat showed wide variation up to levels as high as $15 \mathrm{mEq}$. per $\mathrm{L}$. This lack of any correlation between arm bag and total body concentrations makes only gross approximation of the correct skin losses possible.

The differences between Groups A and B, relative to potassium and nitrogen, should be emphasized. Not only were the differences between the arm bag and total body sweat concentration smaller in Group A ("flushed" group) than in Group B, but Group A showed a smaller spread of arm bag values. These differences between groups might be best explained by the contribution to the sweat in Group B of high potassium and nitrogen containing material that was removed in Group $A$ by the "flushing" period before initiating sweat col- 
lections. This material could be either stagnant or concentrated solutes in the sweat gland lumen or secretions from the sebaceous glands. Cutaneous desquamation is probably of minor importance because the phosphorus concentration in sweat is negligible regardless of the rate of sweating, or the absence of a "flushing" period $(1,2,19,23$, $24,25)$. It would be much higher if a large cellular contribution were present. Furthermore, all sweats were filtered immediately after being collected.

Berenson and Burch (26) recently demonstrated that the highest sweat potassium concentrations were seen in the earliest period of serial sweat collections, and the concentrations then fell to a relatively constant value. The reverse was seen for sodium and chloride concentration. Many years ago Whitehouse, Hancock, and Haldane $(16,25,27,28)$ demonstrated that the lower the sweat rate (below $300 \mathrm{cc}$. per hr.), the greater the potassium to chloride ratio and the higher the organic solids to ashed solids. The contamination of sweat by substances high in potassium best explained these findings. The results of this study and those reported in the literature emphasize the importance of this preliminary "flushing" period before attempting to obtain the "true" sweat concentration of potassium and nitrogen.

Although sweat solute concentrations vary greatly in different body areas, there is no evidence that the arm sweat concentrations of the measured solutes are higher than the concentration of these solutes from other skin areas collected in a similar manner $(4,5,6,14,26)$. It would appear that the environment created under the arm bag led to the differences noted between arm and total body sweat solute concentration.

Ladell found that when sweat was collected from both arms under similar conditions, the chloride concentrations and sweat rates were equal; however, when he compared the inclosed with the uninclosed arm, he found that both the sweat rates and chloride concentrations of the inclosed arm were higher. $\mathrm{He}$, as well as others $(5,7,15)$, noted that the skin temperature of the inclosed arm was always higher than the uninclosed arm or the rest of the skin surface. The positive correlation between skin temperature, sweat sodium, and chloride concentrations, and sweat rate has been stressed in previous studies $(4,5,7,15,29)$.

Although the skin temperature is an important factor in the differences between arm bag and total body sweat concentrations, it is not adequate to explain all the findings. Weiner and van Heyningen (21) found no change in urea concentration with increasing skin temperatures, and lower skin temperatures with lower sweat rates are probably associated with higher potassium concentrations $(2,26,27,28)$. Van Heyningen and Weiner (8) hypothesized that if a single factor within the arm bag affected all the solutes equally, then their concentrations would all change proportionally; therefore, the ratio of the total body concentration of a given solute to the total body concentration of any other solute should equal the ratio of the arm bag concentrations of these same solutes, i.e., $(\mathrm{N})_{a} /\left(\mathrm{Cl}^{-}\right)_{a}$ should equal $(\mathrm{N})_{b} /\left(\mathrm{Cl}^{-}\right)_{b}$. Their correlation coefficients for urea, chloride, and lactate were very high. They concluded that the arm bag environment affects primarily the movement of sweat water, the latter undergoing repenetration or reabsorption through the skin surface. This would, of course, lead to equal degrees of concentration of all sweat solutes. Repenetration of sweat water through the intact skin probably occurs $(16,27,30)$ without solutes (22). This is enhanced by increases in skin temperature and skin blood flow (30) as found within the arm bag.

In an effort to substantiate the findings of van Heyningen and Weiner (8), the arm and body concentrations of the various solutes were correlated in a similar manner. The data are presented in Table III. Many correlations comparable to those of van Heyningen and Weiner were obtained. The sodium to chloride correlations and the potassium to nitrogen correlations were not significant. It would appear that movements of water without solute were important, but other factors must contribute to the difference between the concentration of solutes in arm bag and total body sweat.

Finally, the inclusion of hand or palmar sweat in the collection of arm bag sweat may be of considerable importance in causing differences between the arm bag and total body concentrations found. Palmer and plantar sweat have characteristics that differ markedly from general body sweat. Randall and Hertzman $(31,32)$ and Weiner (33) 
TABLE III

Correlation of solute concentration ratios in the arm sweat (a) with solute concentration ratios in the body sweat $(b)$

\begin{tabular}{|c|c|c|}
\hline $\begin{array}{c}\text { Solutes } \\
\text { correlated }\end{array}$ & $\begin{array}{l}\text { Correlation } \\
\text { coefficients }\end{array}$ & $\begin{array}{l}\text { Level of } \\
\text { significance }\end{array}$ \\
\hline \multicolumn{3}{|c|}{ Group A } \\
\hline$\frac{\mathrm{Cl}^{-}}{\mathrm{Na}^{+}}$vs. $\frac{\mathrm{Cl}^{-}{ }_{b}}{\mathrm{Na}^{+} b_{b}}$ & .515 & Not significant \\
\hline$\frac{\mathrm{K}^{+}}{\mathrm{Na}^{+}}$vs. $\frac{\mathrm{K}^{+}{ }_{b}}{\mathrm{Na}^{+}{ }_{b}}$ & .918 & $P<.01$ \\
\hline$\frac{\mathrm{N}_{a}}{\mathrm{Na}^{+}}$vs. $\frac{\mathrm{N}_{\mathrm{b}}}{\mathrm{Na}^{+}{ }_{\mathrm{b}}}$ & .838 & $P<.01$ \\
\hline$\frac{\mathrm{N}_{\mathrm{a}}}{\mathrm{Cl}^{-}}$vs. $\frac{\mathrm{N}_{\mathrm{b}}}{\mathrm{Cl}^{-} \mathrm{b}}$ & .866 & $P<.01$ \\
\hline$\frac{N_{a}}{K^{+}}$vs. $\frac{N_{b}}{K^{+} b}$ & .603 & $\mathbf{P}<.05$ \\
\hline$\frac{\mathrm{K}^{+} \mathrm{a}}{\mathrm{Cl}^{-}}$vs. $\frac{\mathrm{K}^{+} \mathrm{b}}{\mathrm{Cl}^{-} \mathrm{b}}$ & .921 & $\mathrm{P}<.01$ \\
\hline \multicolumn{3}{|c|}{ Group B } \\
\hline$\frac{\mathrm{Cl}^{-}}{\mathrm{Na}^{+}}$vs. $\frac{\mathrm{Cl}^{-}{ }_{b}}{\mathrm{Na}^{+}{ }_{b}}$ & .509 & $P=.05$ \\
\hline$\frac{\mathrm{K}^{+}}{\mathrm{Na}^{+}}$vs. $\frac{\mathrm{K}^{+}{ }_{\mathrm{b}}}{\mathrm{Na}^{+}{ }_{\mathrm{b}}}$ & .905 & $P<.01$ \\
\hline$\frac{\mathrm{N}_{a}}{\mathrm{Na}^{+}}$vs. $\frac{\mathrm{N}_{\mathrm{b}}}{\mathrm{Na}^{+}{ }_{b}}$ & .812 & $P<.01$ \\
\hline$\frac{\mathrm{N}_{\mathrm{a}}}{\mathrm{Cl}^{-}}$vs. $\frac{\mathrm{N}_{\mathrm{b}}}{\mathrm{Cl}^{-} \mathrm{b}}$ & .851 & $P<.01$ \\
\hline$\frac{\mathbf{N}_{\mathbf{a}}}{\mathrm{K}^{+} \mathbf{a}}$ vs. $\frac{\mathbf{N}_{\mathrm{b}}}{\mathrm{K}^{+} \mathrm{b}_{\mathrm{b}}}$ & .520 & $P<.05$ \\
\hline$\frac{\mathrm{K}^{+}}{\mathrm{Cl}^{-}}$vs. $\frac{\mathrm{K}^{+}{ }_{\mathrm{b}}}{\mathrm{Cl}^{-} \mathrm{b}}$ & .952 & $P<.01$ \\
\hline
\end{tabular}

have shown that not only is sweating continuous at cool temperature on the palms and soles, but palm and sole sweating does not appear to be related to environmental temperatures. In chemical analysis of palmar sweat collected by cannulation, Lobitz and Mason (34) noted chloride concentrations ranging from 100 to $300 \mathrm{mEq}$. per L. and urea concentrations from 68 to $275 \mathrm{mgm}$. per $100 \mathrm{cc}$. of sweat. Since our collections included sweat from the palm, we cannot at this time assess its contribution to the results observed.

\section{SUMMARY AND CONCLUSIONS}

In 27 experiments on 17 healthy, young, white men the sodium, potassium, chloride, and nitro- gen concentrations of total body sweat were compared with their respective concentrations in arm bag sweat. In twelve experiments (Group A) the sweat collections were preceded by a short heat exposure to "flush" the sweat gland lumens and skin. In Group B (15 experiments), no such "flushing" period was used.

The nitrogen and potassium concentrations of arm bag sweat always exceeded the concentrations of these solutes in total body sweat. This difference was exaggerated in the Group B experiments. In neither group could predictable correlations be found between total body and arm bag nitrogen and potassium sweat concentrations. However, in almost all cases the total body sweat concentrations of nitrogen and potassium fell within narrow range of 20 to $40 \mathrm{mgm}$. per cent and 4 to 6 $\mathrm{mEq}$. per L., respectively. The lower the sodium and chloride concentrations were in arm bag sweat, the closer was the agreement with the total body sweat concentrations of these electrolytes.

Regression equations were formulated from these data and the usefulness of these equations for the prediction of total body sweat concentrations of sodium and chloride were discussed. An attempt was made to delineate the technical sources of error and the physiologic variables accounting for the differences between arm bag and total body concentrations noted in this study.

\section{ACKNOWLEDGMENTS}

The authors wish to express their appreciation to Dr. Austin Henschel, Director of Research, QM Climatic Research Laboratory, for his most helpful advice and criticism; and to Miss J. A. Klimas for her statistical evaluation of the data. The technical contributions of Mr. T. F. Maliszewski, Mrs. I. T. Dobalian, Mrs. M. E. Pillion, Mr. A. R. MacLeod, Pfc J. Lopez, Pfc R. Damm, and Pfc R. Bunge are most gratefully acknowledged.

\section{REFERENCES}

1. Mitchell, H. H., and Hamilton, T. S., The dermal excretion under controlled environmental conditions of nitrogen and minerals in human subjects, with particular reference to calcium and iron. $\mathrm{J}$. Biol. Chem., 1949, 178, 345.

2. Unpublished observations.

3. Conn, J. W., and Louis, L. H., Production of endogenous "salt active" corticoids as reflected in the concentrations of sodium and chloride of thermal sweat. J. Clin. Endocrinol., 1950, 10, 12. 
4. Johnson, R. E., Pitts, G. C., and Consolazio, F. C., Factors influencing chloride concentration in human sweat. Am. J. Physiol., 1944, 141, 575.

5. Ladell, W. S. S., The measurement of chloride losses in the sweat. J. Physiol., 1948, 107, 465.

6. Mickelsen, O., and Keys, A., The composition of sweat, with special reference to the vitamins. J. Biol. Chem., 1943, 149, 479.

7. Robinson, S., Gerking, S. D., Turrell, E. S., and Kincaid, R. K., Effect of skin temperature on salt concentration of sweat. J. Appl. Physiol., 1950, 2, 654.

8. van Heyningen, R., and Weiner, J. S., A comparison of arm-bag and body sweat. J. Physiol., 1952, 116, 395.

9. van Heyningen, R., and Weiner, J. S., The effect of arterial occlusion on sweat composition. J. Physiol., 1952, 116, 404.

10. Schales, O., and Schales, S. S., Simple and accurate method for the determination of chloride in biological fluids. J. Biol. Chem., 1941, 140, 879.

11. Peters, J. P., and Van Slyke, D. D., Quantitative Clinical Chemistry, Vol. II., Methods. Williams \& Wilkins, Baltimore, 1932.

12. Conway, E. J., Microdiffusion Analysis and Volumetric Error. C. Lockwood, London, 1947.

13. Dill, D. B., Life, Heat, and Altitude. Harvard Univ. Press, Cambridge, Mass., 1938, p. 45.

14. Hertzman, A. B., and Randall, W. C., The regional rates of evaporation from the skin at various environmental temperatures. Air Force Tech. Report 5951, No. 6680, Part 2.

15. Weiner, J. S., and van Heyningen, R. E., Relation of skin temperature to salt concentration of general body sweat. J. Appl. Physiol., 1952, 4, 725.

16. Whitehouse, A. G. R., Hancock, W., and Haldane, J. S., The osmotic passage of water and gases through the human skin. Proc. Royal Soc., Series B, 1932, 111, 412.

17. Cuthbertson, D. P., and Guthrie, S. W., The effect of variations in protein and salt intake on the nitrogen and chloride content of sweat. Biochem. J., 1934, 28, 1444.

18. McCance, $R$. A., The effect of salt deficiency in man on the volume of the extracellular fluids, and on the composition of sweat, saliva, gastric juice, and cerebrospinal fluid. J. Physiol., 1938, 92, 208.

19. McSwiney, B. A., The composition of human perspiration. Proc. Royal Soc. Med., 1934, 27, 839.

20. Mezinesco, M. D., L'effet de l'acclimatation aux tem- pératures élevées sur la composition de la sueur. Comptes rend. Soc. de biol., 1937, 126, 540.

21. Weiner, J. S., and van Heyningen, R. E., Observations on lactate content of sweat. J. Appl. Physiol., 1952, 4, 734.

22. Folk, G. E., Jr., Penetration of water in the human foot. QM Climatic Research Laboratory Report No. 181, 1951.

23. Bischoff, F., Maxwell, L. C., and Hill, E., Studies in hyperthermia. III. The phosphorus equilibrium. J. Biol. Chem., 1931, 90, 331.

24. Talbert, G. A., Haugen, C., Carpenter, R., and Bryant, J. E., Simultaneous study of the constituents of the sweat, urine and blood; also gastric acidity and other manifestations resulting from sweating. Am. J. Physiol., 1933, 104, 441.

25. Whitehouse, A. G. R., The dissolved constituents of human sweat. Proc. Royal Soc., Series B, 1935, $117,139$.

26. Berenson, G. S., and Burch, G. E., Study of the sodium, chloride and potassium content of thermal sweat of men collected from small isolated areas. Am. J. Med., 1952, 13, 641.

27. Hancock, W., Whitehouse, A. G. R., and Haldane, J. S., The loss of water and salts through the skin, and the corresponding physiological adjustments. Proc. Royal Soc., Series B., 1929, 105, 43.

28. Whitehouse, A. G. R., Further investigation of sweating and sweat. Proc. Royal Soc., Series B, 1931, $108,326$.

29. Locke, W., Talbot, N. B., Jones, H. S., and Worcester, J., Studies on the combined use of measurements of sweat electrolyte composition and rate of sweating as an index of adrenal cortical activity. J. Clin. Invest., 1951, 30, 325.

30. Pinson, E. A., Water exchanges and barriers as studied by the use of hydrogen isotopes. Physiol. Rev., 1952, 32, 123.

31. Randall, W. C., Quantitation and regional distribution of sweat glands in man. J. Clin. Invest., 1946, 25, 761.

32. Randall, W. D., and Hertzman, A. B., The dermatomal recruitment of sweating in response to generalized radiant heating. Air Force Tech. Report No. 6680, 1951, Part 3.

33. Weiner, J. S., The regional distribution of sweating. J. Physiol., 1945, 104, 32.

34. Lobitz, W. C., and Mason, H. L., Chemistry of palmar sweat. VII. Discussion of studies on chloride, urea, glucose, uric acid, ammonia nitrogen and creatinine. Arch. Dermat. \& Syph., 1948, 57, 907. 